\title{
GMR
}

\section{Effects of MMP-1 and MMP-3 gene polymorphisms on gene expression and protein level in lumbar disc herniation}

\author{
B. Eser ${ }^{1}$, O. Eser ${ }^{2}$, Y. Yuksel ${ }^{3}$, H. Aksit ${ }^{4}$, E. Karavelioglu ${ }^{5}$, M. Tosun ${ }^{3}$ \\ and $\mathrm{Z}$. Sekerci ${ }^{6}$ \\ ${ }^{1}$ Department of Medical Genetics, Faculty of Medicine, Balıkesir University, \\ Balıkesir, Turkey \\ ${ }^{2}$ Department of Neurosurgery, Faculty of Medicine, Balıkesir University, \\ Balıkesir, Turkey \\ ${ }^{3}$ Department of Histology and Embryology, Faculty of Medicine, \\ Afyon Kocatepe University, Afyonkarahisar, Turkey \\ ${ }^{4}$ Department of Biochemistry, Faculty of Veterinary Medicine, \\ Balıkesir University, Balıkesir, Turkey \\ ${ }^{5}$ Department of Neurosurgery, Faculty of Medicine, Afyon Kocatepe University, \\ Afyonkarahisar, Turkey \\ ${ }^{6}$ Department of Neurosurgery, \\ Ministry of Health Diskapi Yildirim Beyazit Training and Research Hospital, \\ Ankara, Turkey \\ Corresponding author: B. Eser \\ E-mail: drbetuleser@gmail.com
}

Genet. Mol. Res. 15 (3): gmr.15038669

Received March 29, 2016

Accepted April 8, 2016

Published September 9, 2016

DOI http://dx.doi.org/10.4238/gmr.15038669

Copyright (C) 2016 The Authors. This is an open-access article distributed under the terms of the Creative Commons Attribution ShareAlike (CC BY-SA) 4.0 License.

ABSTRACT. The aim of this study was to identify the possible correlation between polymorphisms in matrix metalloproteinase $(M M P)-1$ and $M M P-3$ and their corresponding protein levels in disc 
tissues obtained from patients with lumbar disc herniation (LDH) using biochemical and immunohistochemical analyses. Blood and disc samples were obtained from 100 patients with LDH who underwent a lumbar microdiscectomy. Based on the radiological degeneration, the patients were diagnosed with grade 2, 3, or $4 \mathrm{LDH}$. MMP-1 $-1607 \mathrm{GG} / 2 \mathrm{G}$ and $M M P-3-11715 \mathrm{~A} / 6 \mathrm{~A}$ were analyzed by real-time polymerase chain reaction. The expressions of $M M P-1$ and $M M P$ 3 were detected by biochemical and immunohistochemical analyses. We found no association between the $M M P-1$ polymorphism and disc degeneration and MMP-1 expression. However, patients expressing the $6 \mathrm{~A} / 6 \mathrm{~A}$ and $5 \mathrm{~A} / 6 \mathrm{~A}$ alleles of $M M P-3-11715 \mathrm{~A} / 6 \mathrm{~A}$ showed higher MMP-3 expression, compared to those expressing the $5 \mathrm{~A} / 5 \mathrm{~A}$ genotype. Additionally, the radiological degeneration grades were correlated with the histological degeneration scoring. Protein levels and immunopositive cell rates of MMP-1 and MMP-3 were associated with disc degeneration grades. Moreover, the MMP-1 and MMP-3 expression and the histological and radiological scores were positively correlated and the $M M P-3-11715 \mathrm{~A} / 6 \mathrm{~A}$ polymorphism was associated with MMP-3 expression in herniated disc tissues. This study is the first to investigate polymorphisms in $M M P-1$ and $M M P-3$, as well as their corresponding protein expressions. We also quantified an association between the radiological degeneration grades and MMP-1 and MMP3 expression. Further genomic studies on $M M P s$ could focus on the utilization of MMP-1 and MMP-3 as markers for the prevention and treatment of this disease.

Key words: Disc herniation; Gene expression; Matrix metalloproteinase; Polymorphism

\section{INTRODUCTION}

Lumbar disc herniation (LDH) is a common, but complex and multifactorial, spine disease affected by various genetic and environmental factors (Solovieva et al., 2002; Chan et al., 2006). Factors such as age, smoking status, occupation, vibration trauma, environmental factors, such as obesity, as well as genetic factors, such as modifications in various genes, play a major role in the etiology of this disease. Previous studies have attempted to identify and analyze the polymorphisms in various genes associated with LDH (Ala-Kokko, 2002). Research into the genes that code for structural components of the disc (nucleus pulposus and annulus fibrosus) form a basis for elucidating the genetics of disc degeneration (Kawaguchi et al., 1999; Videman et al., 2001). Biochemically, the nucleus pulposus and annulus fibrosus consists of a network of collagen molecules interspersed with proteoglycan and water. The nucleus pulposus, in particular, is rich in proteoglycan. The construction-destruction balance of proteoglycans is an important factor affecting disc pathology. Matrix molecules in the disc are destroyed because of enzymatic activity, which in turn negatively affects the disc height and elasticity. Matrix metalloproteinase (MMP)-1 and -3 (MMP-3) are significantly upregulated during disc construction, indicating their major influence on structural modifications in the disc (Bachmeier et al., 2009).

Genetics and Molecular Research 15 (3): gmr.15038669 
$M M P-1$ and $M M P-3$ are located on chromosome 11q23. A guanine insertion/deletion polymorphism ( $1 G / 2 G$ polymorphism) at position -1607 located at the promoter region of $M M P-1$ increases the transcriptional activity of the $M M P-1$ gene (Rutter et al., 1998). On the other hand, a $5 A / 6 A$ polymorphism at position -1711 in the promoter region of $M M P-3$ has been shown to induce a decrease in promoter activity in an in vitro study (Ye et al., 1996).

This study is the first to investigate polymorphisms in $M M P-1$ and $M M P-3$ genes and their effect on the disc tissue. The aim of this study was to determine the effect of polymorphisms in $M M P-1$ and $M M P-3$ genes on the protein expression of MMP-1 and MMP3 in herniated disc tissues.

\section{MATERIAL AND METHODS}

One hundred patients who were treated at the departments of neurosurgery in two different hospitals for radiculopathy were recruited to this study. Patients in whom disease development was less than 3 months were included in this study. On the other hand, patients who performed heavy physical activity, used motor vehicles were exposed to vibration trauma, or who smoked were not included. The patients were subjected to neurological examinations and radiological tests. Additionally, a lumbar magnetic resonance imaging (MRI) (Magnetom 1.5 T; Siemens, Germany) was performed on the sagittal plane, and $5-\mathrm{mm}$ slices were obtained from all patients to assess the degree of herniation and degeneration in the disc. All images were assessed by 2 experienced radiologists who were blinded to the clinical findings. Patients presenting an extruded herniated disc were included in this study. The grade of disc degeneration was determined according to Schneiderman's classification (based on the signal intensity): grade 1, normal signal intensity; grade 2, heterogeneous decreased signal intensity; grade 3, diffuse signal loss; grade 4, lack of signal (Schneiderman et al., 1987). A majority of the patients were diagnosed with grade $2(\mathrm{~N}=33), 3(\mathrm{~N}=35)$, or $4(\mathrm{~N}=32)$ disc degeneration.

The patients were informed about the study prior to the surgery; informed consent forms, approved by the Ethics Committee of the university, were signed by all patients. Peripheral blood was collected from all patients prior to surgery. Genomic DNA was extracted from these blood samples and stored at $-20^{\circ} \mathrm{C}$ until use. Nucleus pulposus were obtained from all patients by lumbar microdiscectomy. A portion of the nucleus pulposus was stored in sterile Eppendorf tubes at $-80^{\circ} \mathrm{C}$. The remaining portions were fixed by $10 \%$ formalin and embedded in paraffin blocks for histological and immunohistochemical analyses.

\section{Genetic analysis}

Genomic DNA was extracted from all samples using the GeneJet DNA Purification kit (Thermo Scientific Labvision Corp, Fremont, CA, USA) according to the manufacturer protocols. Polymorphisms in $M M P-1$ (-1607 1G/2G; rs1799750) and MMP-3 (-1171 5A/6A; rs3025058) were analyzed using the FastStart DNA Master ${ }^{\text {PLus }}$ HybProbe (Roche Diagnostics GmbH, Mannheim, Germany) and specific primers, with the LightCycler ${ }^{\mathbb{B}}$ Nano (Roche Diagnostics $\mathrm{GmbH}$ ), according to the following amplification program: initial denaturation at $95^{\circ} \mathrm{C}$ for $10 \mathrm{~min} ; 45$ cycles at $95^{\circ} \mathrm{C}$ for $10 \mathrm{~s}$ and $60^{\circ} \mathrm{C}$ for $10 \mathrm{~s}$; and a final extension at $72^{\circ} \mathrm{C}$ for $15 \mathrm{~s}$.

Genetics and Molecular Research 15 (3): gmr.15038669 


\section{Histological analysis}

The nucleus pulposus samples were fixed in $10 \%$ neutral formalin and processed using conventional histological procedures. All samples were embedded in paraffin and 5- $\mu \mathrm{m}$ sections were mounted onto slides (classic slides for histochemical analysis and poly-lysinecoated slides for immunohistochemistry). All samples were stained with hematoxylin-eosin (H\&E) and aniline blue-PAS and analyzed under a light microscope (Eclipse E-600; Nikon, Tokyo, Japan) to determine the histological degeneration score (HDS) of disc tissues (Figure 1). Aniline blue-PAS is used to detect the degree of mucoid degeneration, while $\mathrm{H} \& \mathrm{E}$ is used to evaluate the density of, and structural alterations and granular changes in, the cells. All criteria are summarized in Table 1 (Boos et al., 2002). The slides were assessed by two different histologists who were blinded to the clinical and radiological findings.

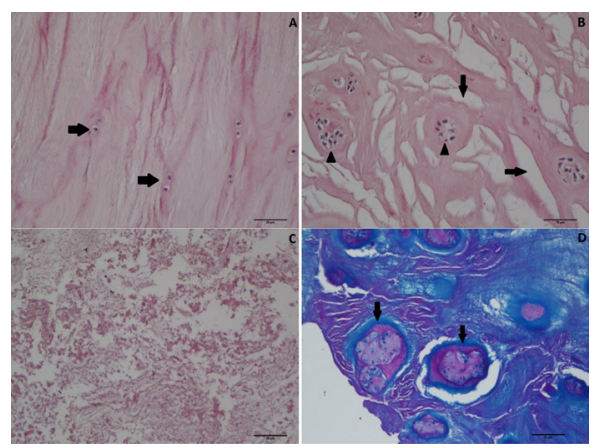

Figure 1. Hematoxylin-eosin and aniline blue-PAS staining. A. Image from a healthy intervertebral disc. A small number of cells (arrows) were observed and the fibers were organized in a parallel order. B. Samples with severe disc degeneration (arrow head) showed increased cell density and huge clones. Structural changes were also observed and the fibrils were fragmented and disorganized. Tears and clefts were seen among the fibrils (arrow). C. Fibrillary/granular degeneration in disc tissue. D. Areas with increased mucous degeneration situated around the cell clones in samples with severe disc degeneration (arrow) were stained a dark blue around the cell clones (20X; scale bar $=50 \mu \mathrm{m})$.

Table 1. Modified parameters of disc degeneration, as reported by Boos et al. (2002).

\begin{tabular}{l|l}
\hline Criteria & Grading \\
\hline Cell density (chondrocyte proliferation): & $0=$ no proliferation \\
Multiple chondrocytes growing in small rounded groups or clusters,, & $1=$ increased cell density \\
sharply demarcated by a rim of territorial matrix & $3=$ small size clones (several chondrocytes grouped together, 3-7 cells) \\
& $4=$ moderately sized clones (8-15 cells) \\
& $5=$ huge clones ( $>15$ cells) \\
\hline Structural alterations (tears and clefts): & $0=$ absent \\
Concentric tears following the collagen fiber bundle orientation in the & $1=$ rarely present \\
annulus fibrosus or radiating defects extending from nucleus pulposus to & $2=$ present in intermediate quantities between 1 and 3 \\
the outer annulus lamellae parallel or oblique to the end plate (clefts) & $3=$ abundantly present \\
& $4=$ scar/tissue defects \\
\hline Granular changes: & $0=$ absent \\
Eosinophilic staining of amorphous granules within the fibrocartilage & $1=$ rarely present \\
matrix & $2=$ present in intermediate quantities between 1 and 3 \\
& $3=$ abundantly present \\
\hline Mucous degeneration: & $0=$ absent \\
Cystic, oval, or irregular areas with intense deposition of acid & $1=$ rarely present \\
mucopolysaccharides, stained dark blue with aniline blue-PAS & $2=$ present in intermediate quantities between 1 and 3 \\
Histologic degeneration score (HDS) $0-15$ points & $3=$ abundantly present \\
\hline
\end{tabular}

Genetics and Molecular Research 15 (3): gmr.15038669 


\section{Immunohistochemical analysis}

Nucleus pulposus samples mounted on polylysine-coated slides were labeled with primary antibodies against MMP-1 and MMP-3, in order to immunohistochemically evaluate the reparation, regeneration, and reorganization of the tissues. The slides were deparaffinized and rehydrated. Antigens were retrieved from the slides by incubating with citrate buffer $(\mathrm{pH}=6.0)$ in a microwave; endogenous peroxidase activity was blocked with $3 \% \mathrm{H}_{2} \mathrm{O}_{2}$ in methanol. Possible non-specific staining was blocked using a protein block provided with a commercial horseradish peroxidase (HRP)-labeled secondary antibody kit (Anti-polyvalent HRP; Thermo Scientific Labvision Corp). Then, the slides were incubated overnight with primary antibodies against MMP-1 (rabbit polyclonal antibody; Thermo Scientific Labvision Corp) and MMP-3 (mouse monoclonal antibody; Merck Millipore, Darmstadt, Germany). The slides were subsequently stained with the HRP-labeled secondary antibody, labeled with the 3-amino-9-ethylcarbazole (AEC) kit, counterstained with Mayer's hematoxylin, and finally mounted with a water-based solution. All chemical solutions were purchased from Thermo Scientific Labvision Corp.

MMP-1 and MMP-3 expression were evaluated by counting 100 cells in different isolated areas from each sample, and calculating the total number of immunopositive cells. The ratio of immunopositive cells to all counted cells was statistically analyzed (Figure 2).

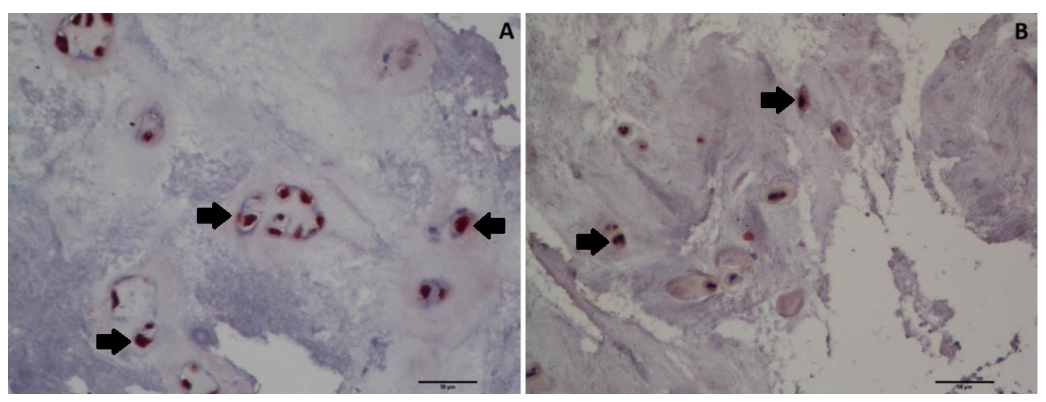

Figure 2. Immunohistochemical staining with primary antibodies against matrix metalloproteinase (MMP)-1 and -3. Degenerated disc cells (arrow) showed strong immunopositivity for MMP-1 (A) and MMP-3 (B) (20X; scale bar $=50 \mu \mathrm{m})$.

\section{Biochemical analysis}

The nucleus pulposus samples stored at $-80^{\circ} \mathrm{C}$ were homogenized with $1.15 \%$ $\mathrm{KCl}$ at a rate of 1/10 using a Stuart SHM 1/UK homogenizer (Bibby Scientific Limited, Staffordshire, UK). The homogenates were centrifuged at $5000 \mathrm{~g}$ for $5 \mathrm{~min}$ and MMP-1 and MMP-3 expression was quantified using a standard MMP-1 ELISA kit (human MMP1 SEA097 Hu ELISA kit; Cloud-Clone Corp, Houston, TX, USA) and MMP-3 ELISA kit (human MMP3 Platinum ELISA; eBioscience, San Diego, CA, USA), respectively, according to the manufacturer protocols.

\section{Statistical analyses}

The grade of degradation and genotypes of $M M P-1$ and $M M P-3$ polymorphisms were

Genetics and Molecular Research 15 (3): gmr.15038669 
compared by the chi-square test. The numeric values obtained by histological and biochemical analyses are reported as means \pm standard deviations (SD) and analyzed by one-way analysis of variance (ANOVA) and Tukey's honest significance difference tests. The correlation between expression levels of $M M P-1$ and $M M P-3$ and the histological and radiological scores of human samples was evaluated by Spearmen's rank correlation coefficient. The significance level was determined as $\mathrm{P}<0.05$.

\section{RESULTS}

Blood and tissue samples of 100 individuals (49 male and 51 female; age range: 23-78; mean age $49.0 \pm 12.5$ ) with lumbar disc herniation were analyzed in this study. Sixteen of the 100 patients recruited to this study were diagnosed with L3-4 disc herniation; of the remaining patients, 59 showed L4-5 and 25 patients were diagnosed with L5-S1 disc herniation. The MMP1 and $M M P-3$ genotypes, biochemical and immunohistochemical expressions of MMP-1 and MMP-3, as well as the radiological degeneration grades were compared among these patients.

We found no association between the genotypes of $M M P-1$ and $M M P-3$ polymorphisms and the disc degeneration grades (Table 2). The genotypes of $M M P-1$ and $M M P-3$ polymorphisms were compared to the levels of MMP-1 and MMP-3 proteins (means \pm SD). While we found no association between the various genotypes of the $M M P-1$ polymorphisms and MMP-1 expression $(\mathrm{P}=0.30)$, the various genotypes of $M M P-3$ polymorphisms and MMP-3 protein expression $(\mathrm{P}=0.006)$ were correlated. Patients expressing the $6 A / 6 A$ and $5 A / 6 A$ genotypes of $M M P-3$ displayed higher MMP-3 levels than those with the $5 A / 5 A$ genotype $(\mathrm{P}=0.004$ and $\mathrm{P}$ $=0.05$, respectively) (Table 3). On the other hand, the genotypes of $M M P-1$ and $M M P-3$ and positive cell ratio of MMP-1 and MMP-3 were not correlated ( $\mathrm{P}=0.78$ and 0.48 , respectively).

Table 2. Different grades of disc degeneration in people expressing the various genotypes of $M M P-1$ and $M M P-3$ polymorphisms.

\begin{tabular}{|c|c|c|c|c|}
\hline Genotypes & Grade $2(\mathrm{~N}=33)$ & Grade $3(\mathrm{~N}=35)$ & Grade $4(\mathrm{~N}=32)$ & $\mathrm{P}$ \\
\hline \multicolumn{5}{|l|}{$M M P-1$} \\
\hline $1 \mathrm{G} / 1 \mathrm{G}$ & 9 & 11 & 5 & \multirow[t]{3}{*}{0.61} \\
\hline $1 \mathrm{G} / 2 \mathrm{G}$ & 14 & 16 & 17 & \\
\hline $2 \mathrm{G} / 2 \mathrm{G}$ & 10 & 8 & 10 & \\
\hline \multicolumn{5}{|l|}{$M M P-3$} \\
\hline $6 \mathrm{~A} / 6 \mathrm{~A}$ & 8 & 9 & 15 & \multirow[t]{3}{*}{0.09} \\
\hline $5 \mathrm{~A} / 6 \mathrm{~A}$ & 19 & 18 & 16 & \\
\hline $5 \mathrm{~A} / 5 \mathrm{~A}$ & 6 & 8 & 1 & \\
\hline
\end{tabular}

Table 3. Comparison of the various genotypes of $M M P-1$ and $M M P-3$ polymorphisms with their corresponding protein levels.

\begin{tabular}{l|c|c}
\hline$M M P-1(\mathrm{~N})$ & MMP-1 & \\
\hline $1 \mathrm{G} / 1 \mathrm{G}(25)$ & $231.24 \pm 230.29$ & \\
\hline $1 \mathrm{G} / 2 \mathrm{G}(47)$ & $345.73 \pm 353.46$ & \\
\hline $2 \mathrm{G} / 2 \mathrm{G}(28)$ & $343.39 \pm 317.86$ & \\
\hline$M M P-3(\mathrm{~N})$ & $\mathrm{MMP}-3$ & \\
\hline $6 \mathrm{~A} / 6 \mathrm{~A}(32)$ & $9.12 \pm 3.48^{*}$ & 0.006 \\
\hline $5 \mathrm{~A} / 6 \mathrm{~A}(53)$ & $8.046 \pm 2.99^{*}$ & \\
\hline $5 \mathrm{~A} / 5 \mathrm{~A}(15)$ & $5.85 \pm 3.13$ & \\
\hline
\end{tabular}

$* \mathrm{P}<0.05$ compared to $5 \mathrm{~A} / 5 \mathrm{~A}$ using the Tukey HSD test.

Genetics and Molecular Research 15 (3): gmr.15038669 
The grades of radiological degeneration and scores of histological degeneration were significantly correlated $(\mathrm{P}<0.001)$. Additionally, the positive cell ratios of MMP-1 and MMP3 were positively correlated with the rates of immunohistochemical expression and grades of degeneration $(\mathrm{P}<0.001)$. Furthermore, an association was detected between the biochemical expression levels of MMP-1 and MMP-3 and the disc degeneration grades $(\mathrm{P}<0.001)$ (Table 4). An analysis of the expression levels of $M M P-1$ and $M M P-3$ compared to the histological and radiological scores revealed a positive correlation between the radiological grades and biochemical and immunohistochemical expressions of MMP-1 and MMP-3 (Table 5).

Table 4. Comparison between disc degeneration grades, histological degeneration scores, and immunohistochemical and biochemical expressions of MMP-1 and MMP-3.

\begin{tabular}{l|c|c|c|c|c}
\hline $\mathrm{G}$ & HDS $($ mean \pm SD) & \multicolumn{2}{|c|}{ \% Stained cells } & \multicolumn{2}{c}{ Protein expression level } \\
\hline & & MMP-1 & MMP-3 & MMP-1 $(\mathrm{pg} / \mathrm{mg})$ & MMP-3 $(\mathrm{ng} / \mathrm{mg})$ \\
\hline 2 & $7.09 \pm 1.01$ & $28.36 \pm 7.05$ & $22.91 \pm 5.75$ & $39.85 \pm 31.93$ & $4.57 \pm 1.55$ \\
\hline 3 & $9.20 \pm 1.08$ & $42.11 \pm 9.98$ & $33.00 \pm 10.79$ & $243.41 \pm 126.58$ & $7.85 \pm 1.34$ \\
\hline 4 & $11.69 \pm 1.45$ & $50.09 \pm 9.53$ & $37.97 \pm 9.86$ & $280.24 \pm 49.54$ & $11.89 \pm 1.58$ \\
\hline $\mathrm{P}$ & $<0.001$ & $<0.001$ & $<0.001$ & $<0.001$ & $<0.001$ \\
\hline
\end{tabular}

HDS, histological degeneration score. G, grade.

Table 5. Correlation of MMP-1 and MMP-3 expression with the histological degeneration score and radiological grades of disc degeneration.

\begin{tabular}{l|c|c|c|c|c|c}
\hline Variables & MMP-3 cells & MMP-3 protein & MMP-1 cells & MMP-1 protein & Grade & HDS \\
\hline Age & -0.024 & 0.015 & -0.023 & 0.017 & 0.054 & 0.061 \\
\hline HDS & $0.591^{* *}$ & $0.810^{* *}$ & $0.646^{* *}$ & $0.790^{* *}$ & $0.874^{* *}$ & \\
\hline Grade & $0.619^{* *}$ & $0.924^{* *}$ & $0.723^{* *}$ & $0.932^{* *}$ & & \\
\hline MMP-1 protein & $0.585^{* *}$ & $0.876^{* *}$ & $0.676^{* *}$ & & & \\
\hline MMP-1 cells & $0.497^{* *}$ & $0.652^{* *}$ & & & & \\
\hline MMP-3 protein & $0.618^{* *}$ & & & & & \\
\hline
\end{tabular}

HDS: histologic degeneration score. *Correlation is significant at the 0.05 level (2-tailed). **Correlation is significant at the 0.01 level (2-tailed).

\section{DISCUSSION}

LDH is a common disease of the spine. Environmental and genetic factors have been reported to play a major role in the pathogenesis of LDH. Previous studies have reported a significant correlation between LDH and polymorphisms in genes coding for aggrecan, vitamin D receptor, collagen, and MMPs (Takahashi et al., 2001; Ala-Kokko, 2002; Cheung et al., 2006; Eser et al., 2010, 2011).

Degradation of the intervertebral disc matrix is an important stage of LDH progression. MMPs are molecules that play a major role in matrix degradation. The MMP family consists of 24 different proteolytic enzymes that are capable of degrading extracellular matrix components. Recent studies have indicated an increase in the expression of MMP enzymes, particularly MMP-1 (collagenase), MMP-2 (gelatinase), and MMP-3 (stromelysin), in degenerated disc tissues (Kang et al., 1996; Nemoto et al., 1997; Haro et al., 2000; Zigouris et al., 2011).

Takahashi et al. (2001) attempted to identify a correlation between disc degeneration and $M M P$ polymorphisms for the first time in $M M P-3(5 A / 6 A)$. The results of this study indicated that the $5 A$ allele of $M M P-35 A / 6 A$ could be representative of disc degeneration in an elderly population. Another study (Song et al., 2008) reported an association between a guanine 
deletion at position -1607 in MMP-1 and disc degeneration in Southern Chinese patients aged 40 years and above with lumbar disc disease. In our study, we discerned no association between polymorphisms in $M M P-1$ and $M M P-3$ and the age of patients. A previous study investigating the association between disc degeneration caused by occupational trauma and polymorphisms in $M M P-3$ suggested that the gene-environment interaction could contribute to the development of lumbar disc degeneration in individuals expressing the $5 \mathrm{~A}$ allele (Yuan et al., 2010). However, we found no association between the various genotypes of MMP-1 and $M M P-3$ and grades of degeneration in this study. Studies conducted on tumor cell lines showed that a guanine insertion allele in $M M P-1$ may increase the transcriptional activity of $M M P-1$, thereby inducing further matrix degradation (Rutter et al., 1998). On the other hand, a study conducted in a Southern Chinese population reported an association between guanine deletion allele and disc degeneration (Song et al., 2008). However, no association was found between the various genotypes of $M M P-1$ and its expression in this study. However, MMP-3 was significantly upregulated in patients expressing the $6 \mathrm{~A}$ allele, compared to those expressing the $5 A / 5 A$ allele.

The mechanism of development of degenerative disc disease has not been understood completely. However, MMPs play a significant role in maintaining the balance between the degradation and synthesis of normal extracellular matrix. Previous studies have researched the expression of MMPs considered to play a key role in the disc degeneration process, via different methods (Sedowofia et al., 1982; Kang et al., 1996; Zigouris et al., 2011). In this study, we analyzed the expression of $M M P-1$ and $M M P-3$ using biochemical and immunohistochemical methods, and observed an agreement between the preoperative radiological degeneration classification and histological and biochemical degeneration of the disc tissue. Moreover, we discovered that patients with a higher disease grade expressed higher enzyme levels and immune positive cell rates. Kang et al. (1996) reported an increase in the MMP-3 (stromelysin) and MMP-2 (gelatinase) production in a herniated disc culture. However, they observed no increase in the MMP-1 (collagenase) activity. On the other hand, higher collagenase activity was reported in another study conducted in disc culture extracts (Sedowofia et al., 1982). In this study, we observed an increase in the MMP-1 and MMP-3 levels in association with the grades of disc degeneration. However, the immunohistochemical results reported in literature vary. Zigouris et al. (2011) detected a correlation between the grades of disc herniation and degeneration scores and $M M P-1$ and $M M P-3$ expression. Canbay et al. (2013) reported a significant association between the histopathological degeneration score and MRI grading in a study carried out in a Turkish population. Le Maitre et al. (2004) reported that MMP-1 and MMP-3 induced an increase in the severity of degenerative nucleus pulposus. However, no association was found between the radiological degeneration scores and MMP-1, MMP-2, and MMP-3 expression in another study conducted in a Turkish population (Ozkanli et al., 2015), while we detected a significant correlation between the grades of degeneration detected by MRI and HDS and $M M P-1$ and $M M P-3$ expressions in this study.

A limited number of studies have analyzed and reported an association between $M M P-1$ and $M M P-3$ polymorphisms and LDH in the literature. Furthermore, the effect of such gene polymorphisms on protein levels in the disc tissue has not been previously investigated. This study is the first to investigate an association between polymorphisms in $M M P-1$ and $M M P-3$ and their protein expressions. Additionally, a large number of herniated disc tissues were analyzed in this study, and two different methods were used to evaluate the $M M P-1$ and $M M P-3$ expressions.

Genetics and Molecular Research 15 (3): gmr.15038669 
Our findings indicate an association between $M M P-3$ polymorphisms and MMP-3 protein expression in herniated disc tissues. Moreover, we detected an agreement between the grades of radiological degeneration and protein levels, as a cause of degeneration in the disc. The major limitation of this study is the small sample size; therefore, we suggest that this study should be replicated in a larger population. Additionally, other polymorphisms in $M M P-1$ and $M M P-3$ and their effect on the resultant mRNA and protein expression should be investigated. Further genomic studies on MMPs could focus on the utilization of MMP-1 and MMP-3 as markers for the prevention and treatment of this disease.

\section{Conflicts of interest}

The authors declare no conflict of interest.

\section{ACKNOWLEDGMENTS}

Research supported by funding provided by Balikesir University (Project \#Tip. BAP.2013.00098). The authors would like to thank A. Said Bodur for the help provided with statistical analysis. This study was presented orally at the $30^{\text {th }}$ Annual Scientific Congress of the Turkish Neurosurgical Society, Antalya, Turkey, 2016.

\section{REFERENCES}

Ala-Kokko L (2002). Genetic risk factors for lumbar disc disease. Ann. Med. 34: 42-47. http://dx.doi. org $/ 10.1080 / 078538902317338634$

Bachmeier BE, Nerlich A, Mittermaier N, Weiler C, et al. (2009). Matrix metalloproteinase expression levels suggest distinct enzyme roles during lumbar disc herniation and degeneration. Eur. Spine J. 18: 1573-1586. http://dx.doi. org/10.1007/s00586-009-1031-8

Boos N, Weissbach S, Rohrbach H, Weiler C, et al. (2002). Classification of age-related changes in lumbar intervertebral discs: 2002 Volvo Award in Basic Science. Spine (Phila. Pa. 1976) 27: 2631-2644.http://dx.doi.org/10.1097/00007632200212010-00002

Canbay S, Turhan N, Bozkurt M, Arda K, et al. (2013). Correlation of matrix metalloproteinase-3 expression with patient age, magnetic resonance imaging and histopathological grade in lumbar disc degeneration. Turk. Neurosurg. 23: $427-433$.

Chan D, Song Y, Sham P and Cheung KM (2006). Genetics of disc degeneration. Eur. Spine J. 15: S317-S325. http:// dx.doi.org/10.1007/s00586-006-0171-3

Cheung KM, Chan D, Karppinen J, Chen Y, et al. (2006). Association of the Taq I allele in vitamin D receptor with degenerative disc disease and disc bulge in a Chinese population. Spine (Phila. Pa. 1976) 31: 1143-1148. http:// dx.doi.org/10.1097/01.brs.0000216530.41838.d3

Eser B, Cora T, Eser O, Kalkan E, et al. (2010). Association of the polymorphisms of vitamin D receptor and aggrecan genes with degenerative disc disease. Genet. Test Mol. Biomarkers 14: 313-317.http://dx.doi.org/10.1089/gtmb.2009.0202

Eser O, Eser B, Cosar M, Erdogan MO, et al. (2011). Short aggrecan gene repetitive alleles associated with lumbar degenerative disc disease in Turkish patients. Genet. Mol. Res. 10: 1923-1930. http://dx.doi.org/10.4238/vol10$\underline{3 g m r 1222}$

Haro H, Crawford HC, Fingleton B, MacDougall JR, et al. (2000). Matrix metalloproteinase-3-dependent generation of a macrophage chemoattractant in a model of herniated disc resorption. J. Clin. Invest. 105: 133-141. http://dx.doi. org $/ 10.1172 / \mathrm{JCI} 7090$

Kang JD, Georgescu HI, McIntyre-Larkin L, Stefanovic-Racic M, et al. (1996). Herniated lumbar intervertebral discs spontaneously produce matrix metalloproteinases, nitric oxide, interleukin-6, and prostaglandin E2. Spine (Phila. Pa. 1976) 21: 271-277. http://dx.doi.org/10.1097/00007632-199602010-00003

Kawaguchi Y, Osada R, Kanamori M, Ishihara H, et al. (1999). Association between an aggrecan gene polymorphism and lumbar disc degeneration. Spine (Phila. Pa. 1976) 24: 2456-2460. http://dx.doi.org/10.1097/00007632-199912010-00006

Genetics and Molecular Research 15 (3): gmr.15038669 
Le Maitre CL, Freemont AJ and Hoyland JA (2004). Localization of degradative enzymes and their inhibitors in the degenerate human intervertebral disc. J. Pathol. 204: 47-54. http://dx.doi.org/10.1002/path.1608

Nemoto O, Yamagishi M, Yamada H, Kikuchi T, et al. (1997). Matrix metalloproteinase-3 production by human degenerated intervertebral disc. J. Spinal Disord. 10: 493-498. http://dx.doi.org/10.1097/00002517-199712000-00006

Ozkanli S, Kaner T, Efendioglu M, Basaran R, et al. (2015). The relation of matrix metalloproteinase 1, 2, 3 expressions with clinical and radiological findings in primary and recurrent lumbar disc herniations. Turk. Neurosurg. 25: 111116.

Rutter JL, Mitchell TI, Buttice G, Meyers J, et al. (1998). A single nucleotide polymorphism in the matrix metalloproteinase-1 promoter creates an ETS binding site and augments transcription. Cancer Res. 58: 5321-5325.

Schneiderman G, Flannigan B, Kingston S, Thomas J, et al. (1987). Magnetic resonance imaging in the diagnosis of disc degeneration: correlation with discography. Spine (Phila. Pa. 1976) 12:276-281.http://dx.doi.org/10.1097/00007632198704000-00016

Sedowofia KA, Tomlinson IW, Weiss JB, Hilton RC, et al. (1982). Collagenolytic enzyme systems in human intervertebral disc: their control, mechanism, and their possible role in the initiation of biomechanical failure. Spine (Phila. Pa. 1976) 7: 213-222. http://dx.doi.org/10.1097/00007632-198205000-00005

Solovieva S, Lohiniva J, Leino-Arjas P, Raininko R, et al. (2002). COL9A3 gene polymorphism and obesity in intervertebral disc degeneration of the lumbar spine: evidence of gene-environment interaction. Spine (Phila. Pa. 1976) 27: 26912696. http://dx.doi.org/10.1097/00007632-200212010-00008

Song YQ, Ho DW, Karppinen J, Kao PY, et al. (2008). Association between promoter -1607 polymorphism of MMP1 and lumbar disc disease in Southern Chinese. BMC Med. Genet. 9: 38. http://dx.doi.org/10.1186/1471-2350-9-38

Takahashi M, Haro H, Wakabayashi Y, Kawauchi T, et al. (2001). The association of degeneration of the intervertebral disc with $5 \mathrm{a} / 6 \mathrm{a}$ polymorphism in the promoter of the human matrix metalloproteinase-3 gene. J. Bone Joint Surg. Br. 83: 491-495. http://dx.doi.org/10.1302/0301-620X.83B4.11617

Videman T, Gibbons LE, Battie MC, Maravilla K, et al. (2001). The relative roles of intragenic polymorphisms of the vitamin d receptor gene in lumbar spine degeneration and bone density. Spine (Phila. Pa. 1976) 26: E7-E12. http:// dx.doi.org/10.1097/00007632-200102010-00003

Ye S, Eriksson P, Hamsten A, Kurkinen M, et al. (1996). Progression of coronary atherosclerosis is associated with a common genetic variant of the human stromelysin-1 promoter which results in reduced gene expression. J. Biol. Chem. 271: 13055-13060.http://dx.doi.org/10.1074/jbc.271.22.13055

Yuan HY, Tang Y, Liang YX, Lei L, et al. (2010). Matrix metalloproteinase-3 and vitamin D receptor genetic polymorphisms, and their interactions with occupational exposure in lumbar disc degeneration. J. Occup. Health 52: 23-30. http:// dx.doi.org/10.1539/joh.L8149

Zigouris A, Batistatou A, Alexiou GA, Pachatouridis D, et al. (2011). Correlation of matrix metalloproteinases-1 and -3 with patient age and grade of lumbar disc herniation. J. Neurosurg. Spine 14: 268-272. http://dx.doi. org/10.3171/2010.9.SPINE09935

Genetics and Molecular Research 15 (3): gmr.15038669 